\title{
A expansão do ensino superior no Brasil: a particularidade dos cursos de Serviço Social no Paraná
}

\author{
The expansion of higher education in Brazil: the particularity of \\ Social Work courses in Paraná
}

\author{
Lorena Ferreira Portes * \\ Jolinda de Moraes Alves **
}

\begin{abstract}
Resumo:
O artigo tem por propósito apresentar o processo de expansão do ensino superior no Brasil, evidenciando o caráter privatista desta expansão que acaba por ser camuflado no discurso da democratização. Através de pesquisa nos dados do Censo da Educação Superior, busca retratar a particularidade da expansão do ensino superior no Paraná, trazendo um mapeamento dos cursos de Serviço Social, caracterizando-os segundo a categoria administrativa e a organização acadêmica. Apresenta uma análise aproximativa sobre os dados explicitando a direção mercantil que se faz notória no processo de expansão do ensino superior no Brasil e, consequentemente, dos cursos de Serviço Social na realidade paranaense.
\end{abstract}

Palavras-Chave: Serviço Social. Ensino Superior. Privatização.

\begin{abstract}
:
The purpose of this article is to present the process of expansion of higher education in Brazil, evidencing its private's character masked in the discourse of democratization. Through a research of data from the Census of Higher Education, it seeks to portray the particularity of the expansion of higher education in Paraná, bringing a mapping of Social Work courses, characterizing them according to the administrative category and the academic organization. It presents an approximate analysis on the data, explaining the commercial direction that becomes evident in the process of expansion of higher education in Brazil and, consequently, of the Social Work courses in the state of Paraná.
\end{abstract}

Key Words: Social Work. Higher Education. Privatization.

\section{Introdução}

O artigo tem como propósito apresentar um levantamento sobre a caracterização dos cursos presenciais de Serviço Social no Brasil, tratando da particularidade da realidade do Estado do Paraná. O interesse por tal temática está imbricado na pesquisa que realizamos no doutorado em Serviço Social e Política Social da Universidade Estadual de Londrina- Pr. Um dos objetivos da pesquisa foi investigar a interferência das

\footnotetext{
* Professora do Departamento de Serviço Social da UEL, Doutora em Serviço Social. E-mail: lorenafportes@gmail.com

** Professora do Departamento de Serviço Social da UEL, Doutora em Serviço Social. E-mail: jolindamalves@gmail.com
} 
condições de trabalho dos/as docentes assistentes sociais na formação profissional e, para tanto, partimos de um mapeamento das escolas de Serviço Social no Paraná, caracterizando-as segundo a categoria administrativa e a organização acadêmica.

Sendo assim, apresentaremos uma análise ainda parcial e aproximativa sobre os dados levantados a partir de pesquisas realizadas através dos relatórios dos Censos de Educação Superior no Brasil e do acesso às informações disponíveis no portal e-mec no mês de março de 2016. A partir do levantamento construiremos uma análise explicitando a direção mercantil que se faz notória no processo de expansão do ensino superior no Brasil e, em particular, nos cursos de Serviço Social no Paraná.

\section{A expansão do ensino superior no Brasil: democratização ou privatismo?}

O ensino superior no Brasil foi marcado nos anos de 1990 por reformas que atenderam aos imperativos das agências internacionais, com destaque para o Banco Mundial, que tiveram um papel fundamental na disseminação de muitas diretrizes que fundamentam a hegemonia neoliberal. Com a proposta de Reforma do Estado elaborada pelo Ministério de Administração e Reforma do Estado - MARE, buscou-se colocar em prática a redefinição das esferas pública e privada através do surgimento de um novo conceito, o de "público não-estatal". O ministro Bresser Pereira defendeu a artimanha alegando que seria preciso modernizar a administração pública, tornando-a mais eficiente sob os critérios do mercado.

Desta forma, no Plano Diretor do MARE (1995), a educação foi colocada no âmbito das atividades não exclusivas de Estado, ou seja, pode ser transferida e melhor executada, do ponto de vista econômico, pelo setor "público não estatal". Processo esse chamado, equivocadamente, de "publicização", onde as instituições de ensino tradicionais organizar-se-iam sob uma nova forma jurídica, as organizações sociais, que celebrariam contratos de gestão com o Estado que reduziria seu papel de prestador direto de serviços, mantendo-se como regulador, provedor e promotor destes.

Nesse cenário, foi dada a partida para as instituições privadas que passaram a empresariar a educação, transformando um direito em mercadoria a ser "comprada". Denuncia Chauí (1999, p. 1), que dessa maneira, " a Reforma encolhe o espaço público democrático dos direitos e amplia o espaço privado não só ali onde isso seria previsível - nas atividades ligadas à produção econômica -, mas também onde não é admissível - 
no campo dos direitos sociais conquistados". A Universidade é atacada, transformandose em um primeiro momento em funcional, como destacada a autora, voltada para a formação rápida de profissionais requisitados como mão de obra altamente qualificada para o mercado de trabalho,

\begin{abstract}
Adaptando-se às exigências do mercado, a universidade alterou seus currículos, programas e atividades para garantir a inserção profissional dos estudantes no mercado de trabalho, separando cada vez mais docência e pesquisa. Enquanto a universidade clássica estava voltada para o conhecimento e a universidade funcional estava voltada diretamente para o mercado de trabalho (CHAUÍ, 1999, p. 4).
\end{abstract}

De funcional passou a ser operacional, regendo-se por contratos de gestão, avaliada por índices de produtividade, calculada para ser flexível, com um processo de formação esvaziado, reduzindo-se à treinamento e à reciclagem, anulando a possibilidade da crítica ao status quo.

Chauí (1999, p. 5) explicita que,

A docência é entendida como transmissão rápida de conhecimentos, consignados em manuais de fácil leitura para os estudantes, de preferência, ricos em ilustrações e com duplicata em CDs. O recrutamento de professores é feito sem levar em consideração se dominam ou não o campo de conhecimentos de sua disciplina e as relações entre ela e outras afins - o professor é contratado ou por ser um pesquisador promissor que se dedica a algo muito especializado, ou porque, não tendo vocação para a pesquisa, aceita ser escorchado e arrochado por contratos de trabalho temporários e precários, ou melhor, "flexíveis". A docência é pensada como habilitação rápida para graduados, que precisam entrar rapidamente num mercado de trabalho do qual serão expulsos em poucos anos, pois tornam-se, em pouco tempo, jovens obsoletos e descartáveis; ou como correia de transmissão entre pesquisadores e treino para novos de pesquisadores. Transmissão e adestramento. Desapareceu, portanto, a marca essencial da docência: a formação.

O processo de reforma do ensino superior no Brasil apresenta uma cultura gerencial que afeta também as instituições públicas. Segundo Netto (2000), um dos traços marcantes dessa cultura é a lógica da racionalização de recursos, a partir da qual o Estado deixa de ter papel central na provisão das políticas sociais, em especial o Ensino Superior, passando a responsabilidade para o mercado, com intuito de enxugar os gastos da máquina estatal. Tal perspectiva possibilita financiamento através das parcerias público-privadas e coloca a pós-graduação e a pesquisa a serviço dos interesses privatistas. 
Igualmente marcante é o direcionamento da gestão para os resultados, a partir do qual a avaliação tem papel fundamental para o credenciamento da Instituição de Ensino Superior - IES, para a realização de sua autonomia e recebimento de recursos. Nesta mesma linha de eficiência e otimização de recursos financeiros, aparece também como baliza a flexibilização. A partir da eliminação do regime jurídico único, do concurso público e da dedicação exclusiva para o exercício da docência, são favorecidos contratos mais ágeis e econômicos. Os resultados são os contratos de docentes "temporários", em regime de trabalho precarizado. Na lógica gerencial a qualidade passa a ser construída e fundamentada na competição e meritocracia, ou seja, a qualidade não pode ser almejada por todas as IES, concentrando-se em alguns centros de excelência.

No Brasil, a opção configurada no Plano Bresser, ao estabelecer a expansão da educação superior pela via privada, introduziu nas IES públicas, uma tendência de mercantilização do trabalho docente. Tal tendência é observada, por exemplo, pelo crescimento dos cursos pagos de pós-graduação lato sensu. Maroneze e Lara, em seus estudos sobre os desafios da política de pessoal da educação, explicam que o trabalho docente não ficou imune às transformações das relações sociais de produção que marcaram as últimas décadas do século XX,

Pode-se afirmar que as novas relações sociais assumidas no contexto da mundialização financeira do capital estabeleceram mudanças no campo da educação, conformando um visível quadro de desvalorização e precarização do trabalho, que se manifesta em consonância com o atual processo de reestruturação do setor produtivo e de redefinição das formas de intervenção do Estado. (MARONEZE; LARA, 2012, p. 119).

Bosi (2007) desenvolveu uma pesquisa sobre o processo de precarização do trabalho docente nas IES considerando como precarização a rotina das atividades de ensino, pesquisa e extensão que compõe propriamente o fazer acadêmico no Brasil, articulando dados relacionados às IES dos setores público (federal, estadual e municipal) e privado (comunitárias, confessionais e particulares).

Segundo o autor o principal marco das mudanças acontecidas no mundo do trabalho que envolveu as atividades docentes situa-se numa crise de acumulação do capital ocorrida em âmbito internacional, por volta do início da década de 1970 (BOSI, 2007). A década de 1990 inaugura um modelo educacional fomentado pela redução do Estado, através da contrarreforma do mesmo, sendo direcionado a sua minimização de 
investimentos sociais e educacionais e à abertura de um terreno vasto e promissor à iniciativa privada.

Os sucessivos governos brasileiros, de Itamar Franco a Dilma Rousseff, adotaram como princípio de suas políticas neoconservadoras, para o financiamento da Educação, a estratégia de fundos financeiros, visando arrefecer os impactos sociais negativos da oferta de educação, fazendo crer que, a partir de então esta alçaria sozinha a condição de redentora dos problemas oriundos da pobreza. (COUTINHO, 2012, p. 148). Foi a partir daí que se iniciou no país essa modalidade de gasto público em educação, idealizado sob a aquiescência de governos nacionais e organismos internacionais.

O processo de privatização, em particular na esfera educacional, abriu precedentes para a desresponsabilização do Estado, ressignificando os conceitos de público, privado e estatal. Nesse sentido, o ensino superior representou uma possibilidade de investimentos e de sucesso financeiro para o capital. Prova dessa abertura foi o imenso crescimento e mercantilização do ensino superior. Como uma das estratégias dessa expansão têm sido os cursos a distância. A entrega do ensino superior para a esfera privada demonstra a integração da política educacional ao gerenciamento das agências internacionais, tornando-se um campo promissor para o mercado.

Analisando a reforma do Estado brasileiro e a lógica gerencial que interfere na política de ensino superior brasileiro, Netto (2000) apresenta cinco traços desta interferência, que não são apenas projetivos, mas que são evidenciados na realidade.

O primeiro traço é o desavergonhado favorecimento à expansão do privatismo, movimento que se instaura no período da ditadura militar, transformando o ensino superior em campo de aplicação do capital. O segundo traço é a liquidação, na academia, da relação ensino/pesquisa/extensão, evidenciando-se na separação desse tripé. A própria LDB dá espaços para essa disjunção a medida em que deixa claro que nem todo ensino superior é responsável por pesquisa. O terceiro traço é a supressão do caráter universalista da universidade. Como quarto traço está a subordinação dos objetivos universitários às demandas do mercado, tornando esse uma das referências da vida acadêmica porque passa a legitimar a eficácia universitária. E, por último, a redução do grau de autonomia universitária, passando a se limitar à autonomia financeira. 
Oportuno mencionar que a expansão e crescimento do ensino superior, travestida pelo discurso de "democratização do acesso à educação", tem desconstruído a educação pública brasileira como um direito social. As reformas no ensino superior e as medidas tomadas pelo governo Cardoso e potencializadas no governo Lula demonstram essa desconstrução. Desde 2003, o governo Lula implementou um conjunto de Medidas Provisórias, Projetos de Lei, Decretos, indicando que a reformulação na educação superior foi uma prioridade em sua pauta de ação política, diz Lima (2012). Destacamos o Programa Universidade para Todos - PROUNI, o Programa de Reestruturação das Universidades Federais (REUNI), o Fundo de Financiamento ao Estudante do Ensino Superior (FIES) e o Ensino a distância (EAD).

Essas medidas evidenciam o empresariamento da educação que se expressa de três formas, como aponta Lima (2012): a) aumento do número de IES, com a expansão das privadas, permanecendo a tendência à privatização da educação superior; b) a privatização nas universidades públicas expressa pela venda de "serviços educacionais" como cursos pagos e parcerias entre empresas e universidades públicas; c) o produtivismo que atravessa e condiciona a política de pesquisa e de pós-graduação: esse processo evidencia a subordinação da ciência à lógica mercantil, incentivando a competitividade e o empreendedorismo pragmático, onde o processo de produção de novos conhecimentos fica atrelado à garantia de concorrência das empresas.

Nesses termos, a educação deixa de ser uma política pública e as instituições de ensino superior, particularmente as universidades, passam a ter outro papel que não o de se constituir como espaço de produção de conhecimento, do debate, da formação de profissionais críticos com fundamento teórico e competência técnica (PINTO, 2012).

O desdobramento desse movimento, para Pinto (2012) é uma profunda alteração do trabalho docente, identificando três componentes centrais desta alteração: a) fragmentação a partir da tipificação entre os docentes, distinguindo-os entre os que pesquisam e os que ensinam; b) precarização do trabalho com um aumento da carga horária em sala de aula, do número de alunos, inclusão de tarefas como critério para remuneração e ausência de política salarial; c) remuneração salarial relacionada à produtividade, cujos critérios são definidos por exigências externas.

Todo esse movimento de reformar o Estado e privatizar os direitos sociais, transformando-os em mercadorias é travestido no discurso de democratizar o acesso à 
educação superior, elevar o nível educacional da população brasileira e fortalecer a democracia. Mas em que condições esse acesso está sendo oportunizado? Para quem? Com qual qualidade? Com quais recursos?

Abre-se ao mercado um campo extremamente lucrativo que é o ensino a distância e o presencial privado. E o papel do Estado nesta expansão, qual seria? O setor privado, para se manter e conseguir essa expansão, necessita da intervenção estatal, através de recursos públicos para financiar direta ou indiretamente as instituições privadas. Como aponta Davies (2002), a "tendência é a de se criar uma burguesia "cativa" na recepção dos mais significativos volumes de recursos". Prova disso, por exemplo, é o disfarce das instituições privadas sob o véu da filantropia, uma vez que a maioria das grandes IES privadas do país não declara ter fins lucrativos.

Respaldando-se na obra de Nicholas Barr, The economics of the Welfare State (1993), que analisa um documento preparado pelo Banco Mundial, em 1998, The financing and management of higher educaction: a status report on worldwide reforms, Sguissardi (2009) discorre e argumenta sobre a tese do ensino superior como bem antes privado que público, estando atrelado, desta forma, às forças do mercado. As consequências desta subordinação, segundo Sguissardi, têm orientado diversas ações nas reformas pontuais da educação superior nos últimos anos, tais como:

a) A gradativa desresponsabilização do Estado com o financiamento e a manutenção da educação superior, embora mantendo sobre ela estrito e crescente controle, via sistemas de avaliação, regulação, controle e credenciamento;

b) O estímulo e as facilidades para a criação e expansão de IES privadas sem e com fins lucrativos;

c) A indução a que as IES públicas sejam organizadas e geridas à semelhança de empresas econômicas;

d) A valorização da qualidade acadêmica em moldes administrativogerenciais e empresariais: produto, custo/benefício;

e) O incentivo à competição intra e interinstitucional;

f) A manutenção das IFES sem autonomia de gestão financeira, e as tentativas de aprovação de instrumentos legais que instituíssem um modelo de autonomia distinto do constitucional, isto é, autonomia financeira em lugar da autonomia da gestão financeira;

g) O implemento à diversificação das fontes de financiamento, mediante, entre outras medidas, a criação de FAls, a cobrança de mensalidades, contratos de pesquisa com empresas, venda de serviços e consultorias, e doações da iniciativa privada;

h) O implemento à diferenciação institucional - universidades de ensino, em especial - além, de carreira docente por instituição, salários individualizados por volume de aulas e de produção científica (SGUISSARDI, 2009, p. 214). 
Desta forma, assistimos ao desmonte do ensino superior na medida em que este tende a seguir a doutrina da flexibilização das atividades, da carreira docente, da desnecessidade da pesquisa científica, da fragmentação das áreas do conhecimento. Essa universidade, diz Chauí (1999, p. 7),

[...] não forma e não cria pensamento, despoja a linguagem de sentido, densidade e mistério, destrói a curiosidade e a admiração que levam à descoberta do novo, anula toda pretensão de transformação histórica como ação consciente dos seres humanos em condições materialmente determinadas.

A expansão do ensino superior no Brasil está condicionada ao seu processo de privatização, em que a educação representa efetivamente uma possibilidade de investimentos e de sucesso financeiro para o capital. Essa expansão e crescimento do ensino superior, travestido pelo discurso de "democratização do acesso à educação", tem desconstruído a educação pública brasileira como um direito social. As reformas no ensino superior e as medidas tomadas pelo governo Fernando Henrique Cardoso e potencializadas no governo Lula e Dilma demonstram essa desconstrução. A entrega do ensino superior para a esfera privada demonstra a integração da política educacional ao gerenciamento das agências internacionais, tornando-se um campo promissor para o mercado ${ }^{1}$. Dando prosseguimento às medidas adotadas pelos seus antecessores, 0 governo de Dilma continuou a expansão do ensino superior, através da ampliação do

\footnotetext{
${ }^{1}$ Explica Martins (2009, p. 24) que entre 1965 e 1980, as matrículas do setor privado saltaram de 142 mil para 885 mil alunos, passando de $44 \%$ do total das matrículas para $64 \%$ nesse período. Em sua fase inicial, ou seja, desde o final dos anos de 1960 até a década de 1970, a expansão do setor privado laico ocorreu basicamente através da proliferação de estabelecimentos isolados de pequeno porte. A partir da segunda metade da década de 1970, o processo de organização institucional do setor privado sofreu uma transformação gradual. Num primeiro momento, alguns estabelecimentos isolados transformaram-se em federações de escolas, através de um processo de fusão. Num momento posterior, a partir do final da década de 1980, o movimento de transformação de estabelecimentos isolados em universidades se acelerou: entre 1985 e 1996, o número de universidades particulares mais do que triplicou, passando de 20 a 64 estabelecimentos. Tudo leva a crer que a expansão das universidades privadas foi orientada pela percepção de seus proprietários de que a existência de estabelecimentos maiores, oferecendo cursos mais diversificados, teria vantagens competitivas no interior do mercado do ensino superior. No início da década de 1990, o ensino privado respondia por $62 \%$ do total das matrículas, ocorrendo uma pequena diminuição em 1995, quando passou a absorver $60 \%$ dos alunos de graduação. A partir dessa data, coincidindo com os dois mandatos de FHC, intensificou-se a presença das instituições particulares no interior do campo do ensino superior. A extinção do CFE, no final do governo Itamar Franco, e a criação do Conselho Nacional de Educação (CNE) conferiram ao MEC uma maior autonomia na condução do processo de expansão do ensino superior. $O$ CNE adotou uma política de flexibilização diante dos processos de autorização, reconhecimento e credenciamento de cursos e de instituições particulares.
} 
Fundo de Financiamento Estudantil - FIES, do Programa Universidade para Todos PROUNI, do Programa de Reestruturação das Universidades Federais (REUNI) e do Ensino a Distância - EAD, decretando também, a construção de novos institutos tecnológicos.

Outro fator desencadeador deste processo foi a regulamentação jurídica da Lei de Diretrizes e Bases da Educação Nacional - LDBEN - de 1996 que propiciou essa adequação do ensino superior aos interesses do mercado, decretando a diversificação das IES, bem como do seu financiamento, a fragmentação e enxugamento dos currículos (substituição de currículo mínimo por diretrizes curriculares), privatização indireta (venda temporária da força de trabalho e dos serviços executados em universidades públicas), perda de autonomia financeira, expansão massiva do ensino privado, incentivo à abertura de cursos sequencias e a distância, reduções orçamentárias e a precarização das unidades de ensino público (OLIVEIRA, 2015).

\section{O caráter privatista e mercantil do ensino superior através dos dados do Censo da Educação Superior no Brasil}

Os dados dos Censos da Educação Superior contribuem na explicitação do viés privatista e mercantil do ensino superior brasileiro como podemos identificar na tabela abaixo.

Tabela 1- Número de IES e matrículas nas IES no Brasil.

\begin{tabular}{ccccc}
\hline ANO & $\begin{array}{c}\text { No total } \\
\text { de IES }\end{array}$ & $\begin{array}{c}\text { No total de IES } \\
\text { privadas }\end{array}$ & $\begin{array}{c}\text { No total de } \\
\text { matrículas }\end{array}$ & $\begin{array}{c}\text { No total de matrículas em } \\
\text { IES privadas }\end{array}$ \\
\hline $\mathbf{2 0 0 2}$ & 1637 & $1442(88,08 \%)$ & 3.479 .913 & $2.428 .258(69,77 \%)$ \\
$\mathbf{2 0 0 3}$ & 1859 & $1652(88,86 \%)$ & 3.887 .022 & $2.750 .652(70,76 \%)$ \\
$\mathbf{2 0 0 7}$ & 2281 & $2032(89,8 \%)$ & 4.880 .381 & $3.639 .413(74,57 \%)$ \\
$\mathbf{2 0 1 0}$ & 2378 & $2100(88,30 \%)$ & 5.449 .120 & $3.987 .424(73,17 \%)$ \\
$\mathbf{2 0 1 3}$ & 2391 & $2090(87,42 \%)$ & 7.305 .977 & $5.373 .450 .(73,54 \%)$ \\
$\mathbf{2 0 1 4}$ & 2368 & $2070(87,41 \%)$ & 7.828 .013 & $5.867 .011(74,94 \%)$ \\
$\mathbf{2 0 1 5}$ & $\mathbf{2 3 6 4}$ & $\mathbf{2 0 6 9 ( 8 7 , 5 2 \% )}$ & $\mathbf{8 . 0 2 7 . 2 9 2}$ & $\mathbf{6 . 0 7 5 . 1 5 2 ( 8 7 , 5 2 \% )}$ \\
\hline
\end{tabular}

Fonte: Dados sistematizados pelas autoras a partir das informações disponibilizadas nos Relatórios do Censo da Educação Superior- INEP (BRASIL, 2016).

Através desses dados podemos identificar o crescimento avassalador do setor privado no âmbito do ensino superior nos últimos anos, chegando em 2015 a alcançar um percentual de quase $88 \%$ em relação ao número de IES existentes e apresentando 
aumento no número de matrículas em IES privadas, subindo de 74,94\% em 2014 para 87,52\% em 2015.

Os dados evidenciam também o crescimento do número de IES ao longo dos últimos 12 anos (entre o último ano de governo de FHC o segundo mandato do governo Dilma), bem como o aumento do número de matrículas realizadas. Sob o discurso da democratização do ensino superior, está o controle da educação (ensino superior) pelo mercado.

Outro dado alarmante está relacionado à organização acadêmica das IES em que há a prevalência de faculdades no Brasil. Os dados do Censo da Educação Superior de 2015 mostram que das 2.364 IES existentes no Brasil, 2069 são privadas. Do total de IES somente 195 são universidades (8,25\%); 149 (6,3\%) são centros universitários; 40 (1,69\%) são caracterizadas como Institutos Federais - IF e CEFETs e 1.980 (83,76\%) são faculdades. Em relação às IES privadas o predomínio das faculdades se faz presente. Das 2.069 IES privadas, somente $88(4,25 \%)$ são universidades; $140(6,76 \%)$ são centros universitários e 1.841 (88,99\%) são faculdades.

Esse processo de privatização do ensino superior caminha ao lado de outro processo que é o de oligopolização. Como forma de ilustrar essa "mercantilização e oligopolização" da educação superior no Brasil valemo-nos de alguns dados significativos trazidos por Oliveira (2015).

A primeira compra de IES pelo capital financeiro foi feita no ano de 2005 , quando a Laureate comprou a Anhembi Morumbi; segundo a CM Consultoria (apud OLIVEIRA, 2015), no ano de 2007 foram feitas 17 fusões e as instituições compradoras foram: Anhanguera, Estácio, Kroton e SEB; no ano de 2008 foram feitas 41 fusões e, entre as instituições compradas, estão as já citadas e IUNI, Laureate (grupo internacional), Cruzeiro do Sul e GP Investimentos (Fundo Private Equity); em 2009 foram realizadas 16 fusões e, entre as instituições acima citadas, a única que aparece é a SEB, as outras são UNOESC, Cartesian Capital Group (Fundo Private Equity), ANIMA, UNIESP, Grupo Campos de Andrade, Advent (Fundo Private Equity), Faculdade Montes Belos DeVry University (grupo internacional); em 2010, Kroton, Laureate, Estácio e Anhanguera voltam a aparecer, juntamente com Capital Internacional (Fundo Private Equity), Multi Brasil S. A., Civita e Grupo Britânico Pearson. 
De acordo com Oliveira (2015), no governo Dilma (2011-2014) foram realizadas 69 fusões, sendo 21 delas no ano de 2011 e 16 em cada um dos anos consecutivos. Entre as instituições compradas que entraram na órbita da compra de IES privadas aparecem: Grupo Saggin Educacional, Abril Educação, UNIBR, ACTIS (Fundo Private Equity), Manning \& Napier Advisors, BR Investimentos, Pollux Capital Administradora, Grupo CETEC Educacional, Grupo Rhema Educação e Escola Satélite, além da Kroton, Anhaguera, Estácio e Ser Educacional (OLIVEIRA, 2015).

Segundo Chaves (2015), a partir de dados obtidos pelo jornal Valor Econômico, os lucros obtidos pelas IES comparam-se aos das empresas de grande porte como a Vale do Rio Doce, a Gerdau e a Petrobrás. Segundo o estudo feito pela Hoper (consultoria especializada na área) e apresentado no G1 (2013), a linha de lucratividade das IES privadas cresceu 30\% em dois anos; o valor de $R \$ 24,7$ bilhões em 2011 saltou para $R \$$ 32 bilhões em 2013.

Importante ressaltar os impactos dessa mercantilização para a formação profissional: uma formação aligeirada, voltada para atender exclusivamente os interesses do mercado, instrumentalizando o ensino superior, afastando-se de uma formação sólida e crítica que acaba por inibir a própria análise da sociedade macroestrutural e os caminhos e tendências que delineiam a funcionalidade do ensino superior no Brasil.

E os rebatimentos no trabalho docente, como se expressam? A proposta de flexibilização da gestão das IES tem favorecido contratos de trabalho mais ágeis e econômicos, como os "temporários", "precários", "substitutos"; o ensino é flexibilizado através de cursos com curta duração, um aligeiramento na formação e também nos currículos, expansão do ensino a distância; novas atribuições são agregadas ao trabalho docente, com a responsabilidade pela captação de recursos, criando um sobretrabalho; as práticas avaliativas são cada vez mais desenvolvidas pelo viés produtivista, acrescentando ao trabalho docente um número indeterminado de procedimentos, como relatórios, preenchimento de formulários, fornecimento de dados para sistema de informação, emissão de pareceres; cria-se uma competição entre os professores, pela instituição da qualidade gerencial no trabalho, fundamentando-se na competência e no mérito, desmantelando-se, desta forma, a dimensão coletiva do trabalho (MANCEBO; FRANCO, 2003). 
Os dados do último Censo do Ensino Superior (BRASIL, 2015) revelam que enquanto nas IES privadas o "típico docente" possui título de mestre e regime de trabalho horista, nas IES públicas, o "típico docente" possui título de doutor e regime de trabalho em tempo integral. No Brasil existem 401.299 docentes no ensino superior, sendo que destes, 226.863 (56,53\%) atuam em IES privadas.

Dos que atuam no setor privado, 14 não possuem graduação, 530 possuem somente a graduação; 70.251 são especialistas (30,96\%); 109.173 são mestres (48,12\%) e 46.895 são doutores (20,67\%). Dos 174.436 docentes que atuam em IES públicas, 20 não possuem graduação; 6.452 possuem somente a graduação; 17.786 são especialistas (10,19\%); 51.631 são mestres (29,59\%) e 98.546 (56,49\%) são doutores. Os dados evidenciam que o perfil docente das IES privadas é de especialista ou mestre, totalizando $79,08 \%$ de docentes, reservando somente $20,67 \%$ de docentes com titulação de doutores. Nas IES públicas teremos outro desenho, sendo que grande parte dos docentes possui titulação de doutor (56,49\%) e secundariamente de mestre $(29,59 \%)$.

Em relação ao regime de trabalho é possível afirmar que há diferenciadas condições de trabalho aos docentes entre os setores público e privado. Do total de 388.004 docentes em exercício no Brasil, 165.722 estão em IES públicas e 222.282 em IES privadas. O regime de trabalho de docentes no setor público é majoritariamente de tempo integral $(83,83 \%$ dos docentes), sendo que no setor privado a predominância é de tempo parcial e horista (38,18\% em tempo parcial e 36,91\% em regime horista), ocorrendo, desta forma, no setor privado, a concentração das atividades em ensino, em detrimento da pesquisa e da extensão.

Estas diferenciações encontram respaldo na legislação que rege a educação no Brasil, uma vez que a LDBEN explicita que somente as instituições universitárias são legalmente obrigadas à realização de pesquisa e somente nelas é obrigatória a existência de "[...] um terço do corpo docente, pelo menos, com titulação acadêmica de mestrado ou doutorado" e [...] um terço do corpo docente em regime de tempo integral" (BRASIL, 1996, art. 52, I e II).

Respaldados na legislação, as instituições, principalmente as privadas, acabam por negligenciar a própria qualificação do seu corpo docente, contratando-os, pela sua titulação, para atender aos critérios mínimos exigidos. Assegurado o mínimo exigido, não se busca ampliar o quadro docente com titulação de mestres e, principalmente, 
doutores. E, também, não se criam condições para que o docente se qualifique e busque ampliar sua titulação, cabendo esta ao esforço individual de cada docente. As políticas de formação docente são cada vez mais escassas, sendo mais negligencias no âmbito privado onde o professor tem pouco incentivo e condições concretas para se qualificar.

As características do ensino superior no Brasil explicitam que as instituições de ensino transitam entre os modelos neonapoleônico e neo-humboldtiano ${ }^{2}$. De acordo com Sguissardi (2004), no primeiro predominam critérios e indicadores como a ausência de estruturas de pesquisa e pós-graduação stricto sensu consolidada e reconhecida; presença majoritária de docentes em regime de tempo parcial ou horista e sem qualificação pós-graduada que habilite para a pesquisa; isolamento das unidades; dedicação quase exclusiva às atividades de ensino; estrutura administrativo-acadêmica voltada para a formação de profissionais.

No segundo modelo, ao contrário, predominam critérios e indicadores como: a presença de estruturas de produção científica e de pós-graduação stricto sensu consolidada e reconhecida; presença majoritária de docentes em regimes de tempo integral e com qualificação pós-graduada que habilite para a pesquisa; integração das unidades em torno de projetos comuns de ensino e pesquisa; associação de ensino, pesquisa e extensão em diferentes níveis; estrutura administrativo-acadêmica voltada para a formação de profissionais e para a formação de pesquisadores na maioria das áreas de conhecimento. (SGUISSARDI, 2004).

Com essa classificação poderíamos afirmar que não é possível pensar em um único modelo de educação superior na realidade brasileira. O que se pode afirmar e facilmente demonstrar é que se está em "presença de uma dualidade ou superposições de modelos" (SGUISSARDI, 2004, p. 42). O modelo neonapoleônico predomina nas faculdades privadas, sem nenhuma obrigação de fazer pesquisa ou de associar ensino, pesquisa e extensão. Mas estariam as instituições públicas, as universidades, atendendo

\footnotetext{
2 O modelo napoleônico ou francês é caracterizado por uma "concepção de instituição de educação superior herdada do lluminismo, marcada pelo elitismo, pela formação profissional em escolas isoladas e pela transmissão do saber." (MOROSINI, 2006, p. 93). Ainda, "nesse modelo, o pressuposto é de que a Universidade deve ser responsável pela formação de profissionais para o atendimento das necessidades da sociedade. Logo, a referência maior é o mundo do trabalho." O modelo humboldtiano ou alemão, segundo Morosini (2006, p. 94), ao contrário do modelo napoleônico, "refere-se à construção do conhecimento em que a pesquisa merece lugar de destaque e a liberdade acadêmica é o seu cerne. É um dos modelos que se fazem presentes nas IES brasileiras, "embora, segundo a autora, o modelo napoleônico seja predominante.
} 
aos critérios do modelo neo-humboldtiano? Questiona o autor: quantas dessas instituições possuem estruturas de pesquisa e pós-graduação consolidadas? Quantas dispõem de um corpo docente predominantemente em regime de tempo integral e com qualificação para a pesquisa? Quantas implementam a associação ensino, pesquisa e extensão para além dos programas e cursos de pós-graduação stricto sensu?

Desta forma, Sguissardi (2004) afirma que, a partir de meados de 1990 o ensino superior adquiriu cada vez mais forma e conteúdo de um modelo neoprofissional, heterônomo e competitivo. Indicadores deste modelo são evidenciados pela expansão do número de IES privadas, muito mais do que o das públicas; a evolução do montante de matrículas no setor privado em relação ao público; a redução do financiamento público; a inserção de critérios competitivos entre os docentes/pesquisadores em relação à gratificação de estímulo à docência; o fortalecimento da competitividade econômica que implicaria na inovação de produtos e processos ligados às necessidades do mercado; o incentivo à criação de fundações privadas nos campi do setor público; a falta de autonomia nas universidades, onde o mercado e o Estado têm aumentado sua capacidade para impor sua própria lógica e interesses; o definhamento do modelo neohumboldtiano, isto é, das universidades de pesquisa ou que associaram pesquisa, ensino e extensão.

\section{O ensino superior no Paraná e a realidade dos cursos de Serviço Social}

A realidade do ensino superior no Paraná obedece à mesma lógica explicitada nos dados apresentados acima, ou seja, o ensino está concentrado nas mãos da iniciativa privada. Os dados do Censo da Educação Superior (BRASIL, 2015) revelam este domínio. No Paraná, das 186 IES existentes, somente 14 são públicas (7,53\%), caracterizando-se pela dominação da iniciativa privada pelo quantitativo de 172 instituições (92,47\% do total da IES no estado).

Enquanto nas IES públicas prevalece, em relação à organização acadêmica, as universidades- 71,42\%- (do total de 14 IES, 10 são universidades, 1 centro universitário, 2 faculdades e 1 IF), nas privadas teremos outra organização, sendo que das 172 IES, somente 5 são universidades, 8 são centros universitários e há o predomínio de faculdades, contando com 159 (92,44\%). 
O predomínio de matrículas em IES privadas é identificado no Paraná, sendo que, das 491.229 matrículas, 355.928 (72,45\%) são em IES privadas: 101.987 em centros universitários (28,65\%), 138.205 em faculdades (28,09\%) e 115.736 (32,51\%) em universidades. Apesar dos dados evidenciarem que ocorre, nos últimos anos, uma mudança em relação à organização acadêmica das IES privadas, migrando de faculdade para centro universitário, o ensino superior no Paraná tem um padrão: é de faculdade privada.

Caracterizando as IES que ofertam cursos de Serviço Social no Brasil (presencial e a distância), temos a seguinte descrição de acordo com o Censo de 2015: 350 IES oferecem o curso de Serviço Social, sendo 61 públicas e 289 privadas; dos 435 cursos oferecidos nestas IES, 61 são em IES públicas e 359 em privadas. Do total de 172.569 matrículas nos cursos de Serviço Social no Brasil, 21.436 estavam em IES públicas e 151.133 matrículas no setor privado.

Em relação à modalidade de ensino, dos 435 cursos, 409 são oferecidos na modalidade presencial e 26 a distância; dos 409 cursos presenciais, 334 são oferecidos em instituições privadas e 75 em instituições públicas. Dos 334 cursos no setor privado, 91 são oferecidos em universidades, 59 em centros universitários e 184 em faculdades. Esta lógica é diferenciada nos cursos oferecidos na modalidade presencial no setor público: 66 cursos em universidades, 8 em faculdades e 1 em IF. Dos 26 cursos a distância, 25 são ofertados por instituições privadas (18 em universidades e 8 em centros universitários) e 1 em universidade estadual pública. (BRASIL, 2016).

Em relação às matrículas nos cursos de Serviço Social na modalidade a distância, em 2007 o número era de 31.115; em 2008 chegou em 101.890; em 2009 diminuiu para 68.055; em 2010 voltou a crescer com a quantidade de 74.474 matrículas; em 2011 foi para 80.650 e em 2012 chegou a 97.428. Tivemos um crescimento no ano de 2008 com a oferta do curso por mais duas instituições, mas que, a partir de 2009 passou a ter um crescimento mais uniforme, sem grandes discrepâncias (PEREIRA; FERREIRA; SOUZA, 2014). Os dados do Censo de 2015 mostram esse crescimento mais uniforme em que o número de matrículas nesta modalidade foi de 96.638.

Já na modalidade presencial, percebe-se uma estabilidade no crescimento de matrículas ao longo dos anos. Em 2007 eram 52.768 matrículas; em 2008 foi de 57.674; em 2009 subiu para 62.124; em 2010 era de 68.724; em 2011 foi para 72.019 e em 2012 
subiu para 75.551 matrículas (PEREIRA; FERREIRA; SOUZA, 2014). Os dados de 2015 revelam esta estabilidade de crescimento, contabilizando-se 75.931 matrículas na modalidade presencial.

A particularidade da realidade paranaense se expressa da seguinte forma: 37 IES ofertam o curso de Serviço Social sendo que destas, 29 são privadas e 8 públicas. Dos 30 cursos oferecidos por estas instituições, 11 estão em IES públicas e 19 em IES privadas. Em relação ao número de matrículas nos cursos de Serviço Social no Paraná, das 4.836 matrículas, 1.331 são no setor público e 3.505 no setor privado.

Em pesquisa realizada no site do e-MEC, em março de 2016, identificou-se que havia 27 cursos na modalidade presencial em efetivo funcionamento (com turmas) oferecidos em 25 IES. Em relação à categoria administrativa das IES que ofertam os cursos presenciais de Serviço Social no Paraná, 68\% (17 IES) são privadas e 32\% (8 IES) são públicas. Sobre a organização acadêmica, 48\% (12) são faculdades, 44\% (11) são universidades e $8 \%$ (2) são centros universitários.

Encontraremos uma diferenciação significativa da organização acadêmica das IES públicas e privadas. Enquanto os cursos de Serviço Social oferecidos no setor público no Paraná estão em universidades, na iniciativa privada eles são ofertados em 12 faculdades, 2 centros universitários e somente em 3 universidades. 71\% das IES privadas que ofertam os cursos de Serviço Social no Paraná caracterizam-se por serem com fins lucrativos e $29 \%$ sem fins lucrativos.

Através dos dados podemos afirmar que a situação dos cursos de Serviço Social obedece à realidade dos cursos de graduação no Brasil: são oferecidos, majoritariamente, em faculdades privadas.

Outro dado relevante é o ano de início de funcionamento dos cursos presenciais no estado. Dos 27 cursos presenciais ativos, identificamos que 05 foram criados antes de 2001; 8 entre 2001 e 2004; 9 entre 2005 e 2009 e 5 entre 2010 e 2015. A expansão do ensino superior no início dos anos 2000 no Brasil também se explicita na realidade paranaense. Percebe-se também que a maioria (22 de 27) dos cursos de Serviço Social no estado foram criados após a aprovação das Diretrizes Curriculares Nacionais em 2001, já nascendo numa conjuntura onde a formação profissional em Serviço Social encontrava-se num grande desafio: formar assistentes sociais com base nas Diretrizes 
aprovadas pela ABEPSS em 1996, mas atacada e esvaziada pelas Diretrizes aprovadas pelo CNE/MEC em 2001.

Dos cursos criados a partir de 2001, 73\% (16 cursos) deles eram ofertados pela iniciativa privada e 27 \% (06 cursos) em instituições públicas. Através da exposição temos elementos para afirmar que o perfil das IES que ofertam os cursos de Serviço Social no Paraná é de ser, predominante mercantil e com possíveis traços do modelo neonapoleônico.

\section{Considerações Finais}

Procuramos evidenciar, a partir dos dados do Censo da Educação Superior no Brasil, que o ensino superior brasileiro carrega e expande uma marca expressiva: o de ser gerenciado e conduzido preponderantemente pela iniciativa privada. Além do fato do mercado dominar a oferta dos cursos de graduação no Brasil, a organização acadêmica das IES privadas que oferecem esses cursos é de ser faculdade. Essa condição põe em questionamento a indissociabilidade entre pesquisa, ensino e extensão, em que a pesquisa se torna um adereço a ser (não obrigatoriamente) desenvolvida nas instituições, uma vez que, de acordo com a LDBEN, nem todo o ensino superior é responsável por pesquisa, somente as instituições universitárias.

Esta preocupação se estende às instituições que ofertam os cursos de Serviço Social no Brasil e, especificamente no Paraná, que obedecem a esse imperativo mercantil. Diante dos dados apresentados urge que pensemos como a formação profissional em Serviço Social está sendo direcionada, uma vez que há uma concentração de faculdades privadas no oferecimento do curso e, também, de que maneira o viés privatista está interferindo na formação profissional nas instituições públicas e, por consequência, nas condições de trabalho dos docentes e no desenvolvimento do tripé: pesquisa, ensino e extensão. São questões que não podem ser postergadas e necessitam de uma problematização.

Compreendemos que o debate sobre os caminhos da formação profissional de assistentes sociais tem que partir da realidade concreta, de como ela se apresenta e não das representações que tecemos sobre ela. Assim, mesmo que tenhamos críticas (e devemos ter) sobre a expansão privatista do ensino superior brasileiro e do crescimento 
da modalidade a distância, não podemos ignorar que esta é a realidade dos cursos de Serviço Social no panorama nacional que se reflete no cenário paranaense.

\section{Referências}

BOSI, Antonio de Pádua. A precarização do trabalho docente nas instituições de ensino superior no Brasil nesses últimos 25 anos. Educação \& Sociedade, Campinas, v. 28, n. 101, p. 1503-1523, set. /dez. 2007.

BRASIL. Instituto Nacional de Estudos e Pesquisas Educacionais Anísio Teixeira.

Sinopses Estatísticas da Educação Superior: 2002, 2003, 2007, 2010, 2013, 2014, 2015. Brasília, 2016. Disponível em: <http://portal.inep.gov.br/superior-censosuperiorsinopse>. Acesso em: 12 jun. 2017.

BRASIL. Lei no 9.394, de 20 de dezembro de 1996. Estabelece as diretrizes e bases da educação nacional. Brasília, 1996. Disponível em: <http://www.presidencia.gov.br/ CCIVIL/LEIS/L9394.htm\#art44>. Acesso em: 20 mar. 2016.

BRASIL. Ministério da Educação e Cultura. Cadastro e-MEC de Instituições e Cursos de Educação Superior, base de dados oficial e única de informações relativas às Instituições de Educação Superior - IES e cursos de graduação do Sistema Federal de Ensino. Brasília, 2017.

CHAUÍ, Marilena. A universidade operacional. Folha de São Paulo, São Paulo, 9 maio 1999. Caderno Mais! p. 3

CHAVES, Vera Lucia Jacob. Expansão da privatização/mercantilização do ensino superior brasileiro: a formação dos oligopólios. Educação \& Sociedade, Campinas, v. 31, p. 481-500, 2010.

COUTINHO, Adelaide F. Educação sob a lógica do mercado: políticas de financiamento e parcerias com o setor privado. IN: COUTINHO e LOPES (orgs). Crise do capital, lutas sociais e políticas públicas. São Paulo: EJR Xama Editora, 2012. p. 147-167.

DAVIES, Nicholas. Mecanismos de financiamento: a privatização dos recursos públicos. In: NEVES, L. (Org.). O empresariamento da educação: novos contornos do ensino superior no Brasil dos anos de 1990. São Paulo: Xamã, 2002. p.151-176.

LIMA, Kátia. Expansão da Educação Superior Brasileira na primeira década do novo século. In: PEREIRA, Larissa Dahmer; ALMEIDA, Ney Luiz Teixeira de. Serviço Social e Educação. Rio de Janeiro: Lunen Juris, 2012. (Coletânea Nova de Serviço Social).

MANCEBO, Deise; FRANCO, Maria Stela Dal Pai. Trabalho docente: uma análise das práticas intelectuais em tempos de globalização. In: DOURADO, Luiz Fernandes; CATANI, Afrânio Mendes; OLIVEIRA, João Ferreira de. (Org.). Políticas e gestão da educação superior: transformações recentes e debates atuais. São Paulo: Xamã, Alternativa, 2003. p. 191-204. 
MARONEZE, Luciane Francielli Zorzetti; LARA, Ângela Mara de Barros. A política de pessoal da educação e os desafios da precarização do trabalho dos professores na rede estadual de educação básico do Paraná (1995-2002). In: DEITOS, Roberto Antonio; LARA, Angela Mara de Barros. Políticas Educacionais: um exame de proposições e reformas educacionais. Cascavel: EDUNIOESTE, 2012.

MARTINS, Carlos Benedito. A Reforma universitária de 1968 e a abertura para o ensino superior privado no Brasil. Educação \& Sociedade, Campinas, v. 30, n. 106, p. 15-35, jan./abr. 2009.

MOROSINI, Marilia Costa. A universidade no Brasil: modelos e concepções. Brasília: Instituto Nacional de Estudos e Pesquisas Educacionais AnísioTeixeira, 2006.

NETTO, José Paulo. Reforma do Estado e Impactos no Ensino Superior. Revista Temporalis, Niterói, Ano 1, n. 1, jan./jun., 2000.

OLIVEIRA, Inaê Soares. A educação vai ao mercado: considerações sobre mercantilização do ensino superior brasileiro. Universidade e Sociedade, n. 56, Ano 24, n. 56, p. 72-83, ago. 2015.

PEREIRA, Larissa Dahmer; FERREIRA, Andreza Telles dos Santos; SOUZA, Andréa Cristina Viana de. Análise comparativa entre expansão dos cursos de Serviço Social EAD e Presenciais. Revista Temporalis, Niterói, Ano 14, n. 27, p.181-202, jan. /jun. 2014.

PINTO, Marina Barbosa. Precarização do trabalho docente: competitividade e fim do trabalho coletivo. In: PEREIRA, Larissa Dahmer; ALMEIDA, Ney Luiz Teixeira de. Serviço Social e Educação. Rio de Janeiro: Lumen Juris, 2012. (Coletânea Nova de Serviço Social).

SGUISSARDI, Valdemar. A universidade neoprofissional, heterônoma e competitiva. IN: FÁVERO, A. L. A.; MANCEBO, D. (Org.). Universidade: políticas, avaliação e trabalho docente. São Paulo: Cortez, 2004.

SGUISSARDI, Valdemar. Universidade brasileira no século XXI: desafios do presente. São Paulo: Cortez, 2009. 